\title{
Accuracy of transcutaneous bilirubin on covered skin in preterm and term newborns receiving phototherapy using a JM-105 bilirubinometer
}

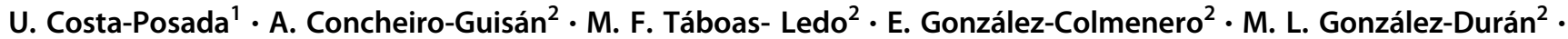 \\ M. Suarez-Albo ${ }^{2} \cdot$ C. Duran Fernández-Feijoo ${ }^{2} \cdot$ M. Pumarada-Prieto ${ }^{2} \cdot$ Cristina Martínez-Reglero $^{3}$. \\ J. R. Fernández-Lorenzo²
}

Received: 4 August 2019 / Revised: 7 October 2019 / Accepted: 7 November 2019 / Published online: 25 November 2019

(c) The Author(s) 2019. This article is published with open access

\begin{abstract}
Objective Determine the suitability of transcutaneous bilirubin (TCB) as a tool to assess the effectiveness of phototherapy on patched skin.

Study design A prospective observational study was conducted. We covered a fragment of skin (sternum) with a photoopaque patch. Several simultaneous TCB and TSB measurements were performed with the JM-105 bilirubinometer. Bland and Altman test evaluated the agreement between bilirubin levels.

Result A total of 217 patients were studied, $48.8 \%$ were preterm. The mean difference between TSB and TCB before the start of treatment was $1.07 \mathrm{mg} / \mathrm{dL}$. During phototherapy, differences on covered skin were $0.52,0.27$, and $0.39 \mathrm{mg} / \mathrm{dL}$ at 24 , 48 , and $72 \mathrm{~h}$ of therapy respectively. The best correlation was observed at $48 \mathrm{~h}$ in preterm infants.

Conclusion The measurement of TCB on patched skin (PTCB) is useful for monitoring the response to phototherapy in term and preterm infants. We use a patch with a removable flap that eases successive measures without disturbing the patients.
\end{abstract}

\section{Introduction}

Jaundice is a frequent and usually physiological problem in the neonate. However, it can become serious and produce neurological sequelae. Up to $10 \%$ of full-term newborns and $25 \%$ of preterm develop significant hyperbilirubinemia that requires phototherapy. Patients undergoing phototherapy require frequent monitoring of serum bilirubin levels to monitor response. A noninvasive alternative is the determination of transcutaneous bilirubin (TCB). The new transcutaneous bilirubinometers use multiwavelength spectral reflectance to measure the optical density of cutaneous

$\triangle$ U. Costa-Posada

Uxia.Costa.Posada@ sergas.es

1 Department of Pediatrics, Alvaro Cunqueiro Hospital, Vigo, Spain

2 Department of Neonatology, Alvaro Cunqueiro Hospital, Vigo, Spain

3 Department of Methodology and Statitics, Alvaro Cunqueiro Hospital, Vigo, Spain bilirubin and present greater precision than former devices [1]. Over the years, a close correlation has been demonstrated between TCB and serum bilirubin (TSB), the first is being currently used as a screening method for suspected neonatal jaundice [2]. However, until now, the use of TCB is not recommended once phototherapy has started as the lightening of the exposed skin decreases its reliability [3, 4]. For this reason, some published studies have evaluated whether the measurement of TCB in covered skin (PTCB) could maintain the correlation with TSB. These studies show contradictory results and some of them include a limited number of patients, especially as regards preterm infants $[3,5,6]$. Most of them shared the same model of bilirubinometer, together with a concrete patch, both different to our study's.

The present study was designed with the objective of evaluating the correlation existing between the TCB, measured with a specific bilirubinometer on covered skin with an alternative removable patch, and the TSB during the treatment with phototherapy. We have evaluated if this measurement is affected by either the length of phototherapy or the patient's gestational age. 


\section{Methods}

This study was carried out in the Neonatology Unit of a level III hospital that receives around 3800 births per year. The study population included term and preterm infants ( $<37$ weeks) who met the inclusion criteria: diagnosis of hyperbilirubinemia and indication of treatment with phototherapy during the period of study (June 2016-June 2018).

We established the indication to start phototherapy after Bhutani modified normogram for term and preterm infants. This normogram takes into account TSB values, hours of life, and gestational age to determine the level of hyperbilirubinemia that goes into the range to start phototherapy [2].

During the treatment with phototherapy (Lullaby LED Ohmeda medical ${ }^{\circledast} / \mathrm{NeoBLUE}$ blanket LED Natus ${ }^{\circledR}$ ) the neonates remained naked, with diaper and eye protection. In addition, part of the anterior thorax (sternum) was covered with an opaque photo-reflective aluminum patch (Heat Reflecting Patch, Ohmeda medical ${ }^{\circledR}$ ) (Fig. 1) which has a flap that can be easily removed and that is not adhered to the skin of the newborn. In each patient, several sets of simultaneous TCB and TSB measurements were performed. The bilirubinometer used was the model JM-105 (Dräger Medical Systems ${ }^{\circledast}$ ).

Prior to the start of phototherapy, a single TCB determination was made at the sternum and, after phototherapy, TCB determinations were made in two locations: on the skin under the patch, and on the exposed naked skin close to it. TSB was determined by diazo-reaction technique. Subsequently, both types of measurements (TCB and TSB) were prospectively collected at 24,48 , and $72 \mathrm{~h}$ of treatment.

Informed consent to participate in this study was signed by both parents of every child and approved by our Local Ethics Committee.

Data analysis was performed by the biostatisticians from the Galicia Sur Health Research Institute (IISGS), who employed the SPSS programme (IBM SPSS Statistics 23.0). The method of Bland and Altman was used to evaluate the agreement between bilirubin levels in blood and skin.

\section{Results}

A total of 217 patients were studied, $111(51.2 \%)$ were fullterm and $106(48.8 \%)$ were preterm (27-36 +6 weeks). The demographic and perinatal characteristics of the patients are shown in Table 1 . All the patients were Caucasian. Hyperbilirubinemia was considered idiopathic in $82 \%$ of infants and related to $\mathrm{AB} 0$ isoimmunisation in $18 \%$. The mean age at the beginning of phototherapy was $68.2 \mathrm{~h}$ of life and the mean duration of therapy $54.5 \mathrm{~h}$. The mean difference of bilirubin levels with respect to the blood

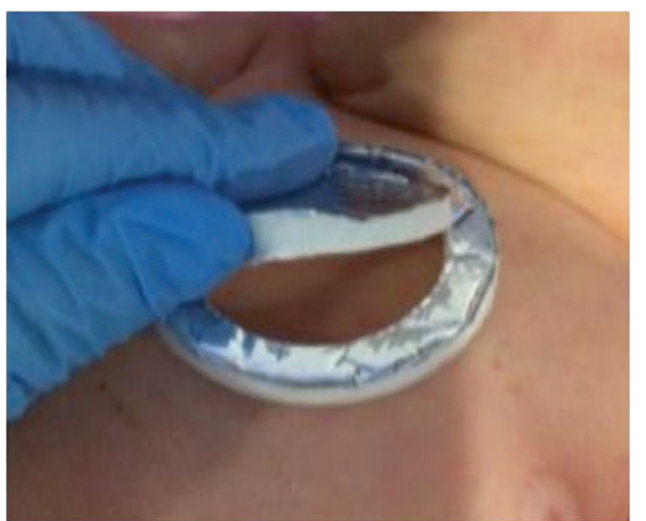

Fig. 1 Photo-opaque patch with an easy-removable flap placed at newborn's sternum (Informed consent was obtained for this picture)

Table 1 Demographic and perinatal characteristics of our patients

\begin{tabular}{lll}
\hline & Preterm neonates & Term neonates \\
& $N=106(48.8 \%)$ & $N=111(51.2 \%)$ \\
\hline Mean weight at birth (g) & 2219.81 & 3182.57 \\
Female (\%) & 47.2 & 45.9 \\
Cesarean section (\%) & 35.8 & 9 \\
Intensive care provided (\%) & 38.7 & 9.9 \\
Weight loss since birth to the & 4.46 & 3.3 \\
time phototerapy was & & \\
started (\%) & & \\
\hline
\end{tabular}

Table 2 Distribution of all patients $(N)$ along the time of the study

Number Pretreatment After $24 \mathrm{~h}$ of After $48 \mathrm{~h}$ of After $72 \mathrm{~h}$ of of patients photherapy photherapy photherapy $(N)$

\begin{tabular}{lllll}
\hline Term & $90 \mathrm{pt}$ & $54 \mathrm{pt}$ & $31 \mathrm{pt}$ & $16 \mathrm{pt}$ \\
Preterm & $54 \mathrm{pt}$ & $54 \mathrm{pt}$ & $19 \mathrm{pt}$ & $10 \mathrm{pt}$ \\
Total & $144 \mathrm{pt}$ & $108 \mathrm{pt}$ & $50 \mathrm{pt}$ & $26 \mathrm{pt}$ \\
\hline
\end{tabular}

exchange transfusion indication threshold was $6.06 \mathrm{mg} / \mathrm{dL}$ (SD 2.82) and no patient in the study did exceed this threshold. Not all patients in the study were subjected to all TCB and TSB determinations because in some cases they finished the therapy earlier or they lacked a simultaneous determination of TSB. For example, only 144 patients out of 217 underwent a simultaneous determination of TSB and TCB before the start of phototherapy. In total, 512 TCB measurements were analyzed, 368 of them during the use of phototherapy and in two locations (covered skin and exposed skin). Table 2 shows the patients distribution during the different times in the study.

In Tables 3-5 we present our main findings according to the mean of differences between TCB and TSB obtained at each time interval of the study for term and preterm 
Table 3 Mean of the differences between UTCB or PTCB (0, 24, 48 , and $72 \mathrm{~h}$ ) and TSB, SD, and IQ range $95 \%$ for term infants

\begin{tabular}{|c|c|c|}
\hline Phototherapy length & UTCB-TSB & PTCB-TSB \\
\hline $0 \mathrm{~h}$ & $\begin{array}{l}1.33 \mathrm{mg} / \mathrm{dl}(\mathrm{SD} 1.84) \\
\text { IQ range } 95 \%: 0.95-1.72\end{array}$ & ---------------------------' \\
\hline $24 \mathrm{~h}$ & $\begin{array}{l}8.69 \mathrm{mg} / \mathrm{dl}(\mathrm{SD} 3.03) \\
\text { IQ range } 95 \%: 7.68-9.70\end{array}$ & $\begin{array}{l}0.74 \mathrm{mg} / \mathrm{dl}(\mathrm{SD} 2.29) \\
\text { IQ range } 95 \%: 0.11-1.37\end{array}$ \\
\hline $48 \mathrm{~h}$ & $\begin{array}{l}6.94 \mathrm{mg} / \mathrm{dl}(\mathrm{SD} 3.19) \\
\text { IQ range 95\%: } 5.29-8.58\end{array}$ & $\begin{array}{l}0.29 \mathrm{mg} / \mathrm{dl}(\mathrm{SD} 1.26) \\
\text { IQ range } 95 \%:-0.16-0.76\end{array}$ \\
\hline $72 \mathrm{~h}$ & $\begin{array}{l}8.31 \mathrm{mg} / \mathrm{dl}(\mathrm{SD} 1.88) \\
\text { IQ range 95\%: } 6.74-9.88\end{array}$ & $\begin{array}{l}0.75 \mathrm{mg} / \mathrm{dl}(\mathrm{SD} 1.76) \\
\text { IQ range } 95 \%:-0.19-1.69\end{array}$ \\
\hline
\end{tabular}

Mean of the differences between UTCB or PTCB $(0,24,48$, and $72 \mathrm{~h})$ and TSB, SD, and IQ range $95 \%$ for term infants

$U T C B$ transcutaneous bilirubin on naked skin, $P T C B$ transcutaneous bilirubin on patched skin, TSB serum bilirubin, $S D$ standard deviation $I Q$ interquartile

\begin{tabular}{lll}
\hline Phototherapy length & UTCB-TSB & PTCB-TSB \\
\hline $0 \mathrm{~h}$ & $0.64 \mathrm{mg} / \mathrm{dl}(\mathrm{SD} 1.84)$ & \\
& IQ range 95\%: 0.13-1.14 & \\
$24 \mathrm{~h}$ & $6.33 \mathrm{mg} / \mathrm{dl}$ (SD 2.72) & $0.29 \mathrm{mg} / \mathrm{dl}$ (SD 1.35) \\
& IQ range 95\%: 5.02-7.64 & IQ range 95\%: 0.29-0.66 \\
$48 \mathrm{~h}$ & $5.61 \mathrm{mg} / \mathrm{dl}(\mathrm{SD} 2.53)$ & $0.24 \mathrm{mg} / \mathrm{dl}$ (SD 1.46) \\
& IQ range 95\%: $-0.66-11.89$ & IQ range 95\%: $-0.38-0.87$ \\
$72 \mathrm{~h}$ & $6.32 \mathrm{mg} / \mathrm{dl}$ (SD 1.94) & $-0.18 \mathrm{mg} / \mathrm{dl}$ (SD 1.76). \\
& IQ range 95\%:-11.14-23.79 & IQ range 95\%: $-0.82-0.46$ \\
\hline
\end{tabular}

$U T C B$ transcutaneous bilirubin on naked skin, $P T C B$ transcutaneous bilirubin on patched skin, TSB serum bilirubin, $S D$ standard deviation, $I Q$ interquartile

\begin{tabular}{|c|c|c|}
\hline Phototherapy length & UTCB-TSB & PTCB-TSB \\
\hline $0 \mathrm{~h}$ & $\begin{array}{l}1.07 \mathrm{mg} / \mathrm{dl}(\mathrm{SD} 1.86) \\
\text { IQ range } 95 \%: 0.77-1.38\end{array}$ & \\
\hline $24 \mathrm{~h}$ & $\begin{array}{l}7.89 \mathrm{mg} / \mathrm{dl}(\mathrm{SD} 3.11) \\
\text { IQ range 95\%: } 7.05-8.73\end{array}$ & $\begin{array}{l}0.52 \mathrm{mg} / \mathrm{dl}(\mathrm{SD} 1.88) \\
\text { IQ range } 95 \%: 0.16-0.88\end{array}$ \\
\hline $48 \mathrm{~h}$ & $\begin{array}{l}6.74 \mathrm{mg} / \mathrm{dl}(\mathrm{SD} 3.08) \\
\text { IQ range 95\%: } 5.30-8.18\end{array}$ & $\begin{array}{l}0.27 \mathrm{mg} / \mathrm{dl}(\mathrm{SD} 1.26) \\
\text { IQ range } 95 \%:-0.08-0.63\end{array}$ \\
\hline $72 \mathrm{~h}$ & $\begin{array}{l}7.91 \mathrm{mg} / \mathrm{dl}(\mathrm{SD} 1.97) \\
\text { IQ range } 95 \%: 6.50-9.32\end{array}$ & $\begin{array}{l}0.39 \mathrm{mg} / \mathrm{dl}(\mathrm{SD} 1.54) \\
\text { IQ range } 95 \%:-0.23-1.01\end{array}$ \\
\hline
\end{tabular}

$U T C B$ transcutaneous bilirubin on naked skin, $P T C B$ transcutaneous bilirubin on patched skin, TSB serum bilirubin $S D$ standard deviation, $I Q$ interquartile
Table 5 Mean of the differences between UTCB or PTCB (0, 24, 48 , and $72 \mathrm{~h}$ ) and TSB, SD, and IQ range $95 \%$ for all infants
Table 4 Mean of the differences between UTCB or PTCB (0, 24 IQ range $95 \%$ for preterm infants patients. Figures 2 and 3 show Bland-Altman plots after 24 and $48 \mathrm{~h}$ of phototherapy, respectively.

In summary, we have found a good correlation between TSB and TCB before the start of treatment. After the initiation of phototherapy, the good correlation between TSB and TCB continued for measurements on skin covered with a patch at 24,48 , and $72 \mathrm{~h}$ of therapy, both for preterm and term children. However, a significant loss of reliability of TCB on uncovered skin was observed. The difference between TCB on exposed and unexposed skin with respect to TSB reached statistical significance at 24 and $48 \mathrm{~h}(p<$ $0.001)$ and at $72 \mathrm{~h}(p<0.01)$ (Fig. 4). Maximum agreement was reached at $48 \mathrm{~h}$ (Figs. 2-4, Tables 3-5). The correlation was better in preterm infants. The agreement remained stable at hyperbilirubinemia levels, even those above $15 \mathrm{mg} / \mathrm{dL}$. None of the patient's perinatal characteristics (Table 1) influence the degree of correlation between TCB and TSB.

\section{Discussion}

To date, after the study by Zecca et al. [7], this is the largest series of patients published using TCB with a photo-skin 

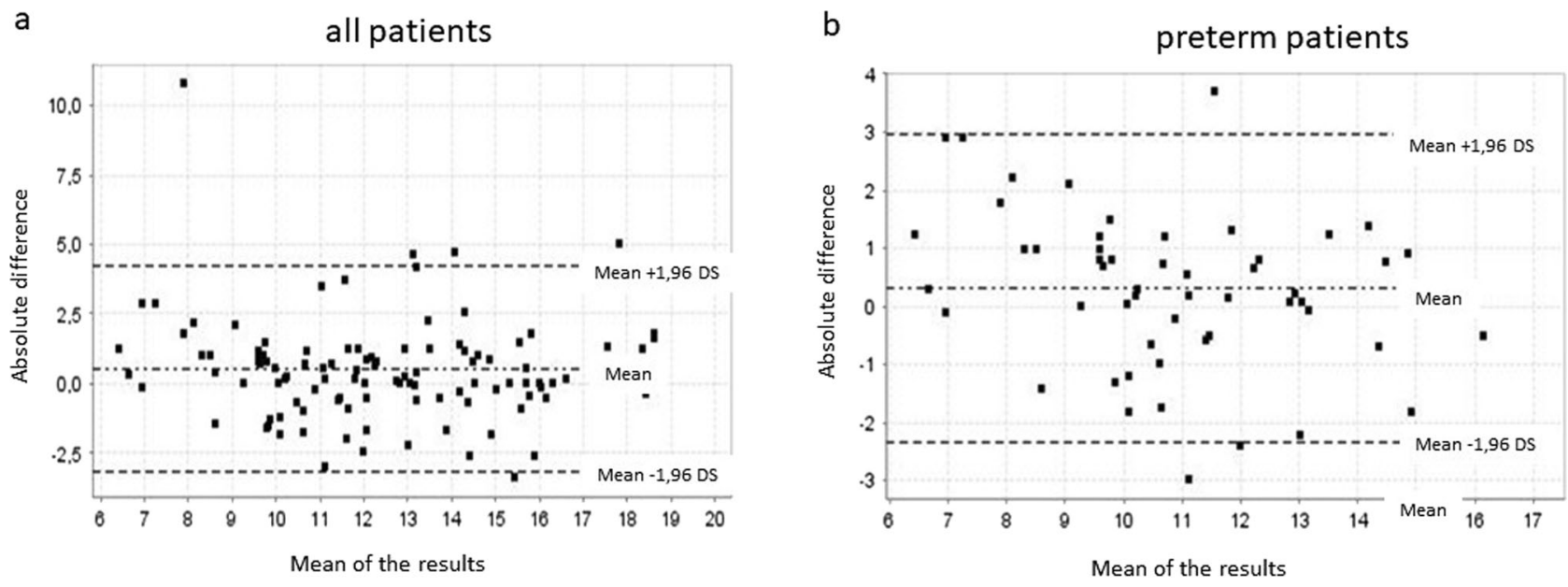

PTCB: patched skin transcutaneous bilirubin. TSB total serum bilirrubin. UTCB: unpatched skin transcutaneous bilirrubin

Fig. 2 Bland-Altman plots. Agreement between PTCB and TSB after $24 \mathrm{~h}$ of phototherapy, (a) total (b) preterm. The $x$-axis shows the mean of the results ([TSB + PTCB]/2; [TSB + UTCB]/2) of the two methods. The $y$-axis shows the absolute difference between the two methods (TSB-PTCB; TSB-UTCB) a

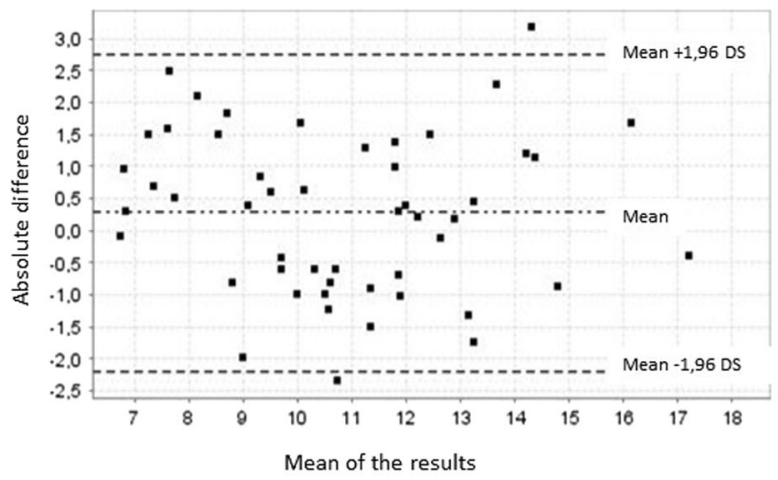

b

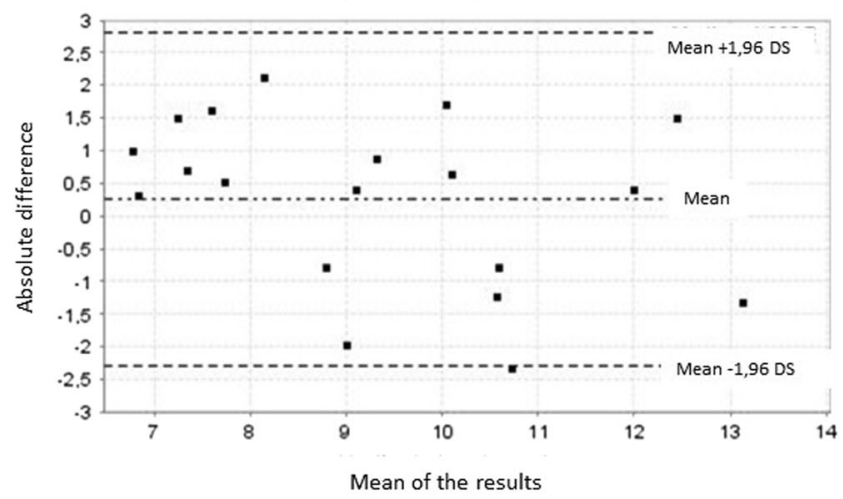

PTCB: patched skin transcutaneous bilirubin. TSB total serum bilirrubin. UTCB: unpatched skin transcutaneous bilirrubin

Fig. 3 Bland-Altman plots. Agreement between PTCB and TSB after $48 \mathrm{~h}$ of phototherapy, (a) total (b) preterm. The $x$-axis shows the mean of the results ([TSB $+\mathrm{PTCB}] / 2 ;[\mathrm{TSB}+\mathrm{UTCB}] / 2)$ of the two

coverage system. This is also the series with the largest number of TCB determinations recorded on covered skin and the second in terms of the number of preterm infants included. Considering that the majority of studies using a skin cover have been performed with the Bilicheck ${ }^{\circledR}$ device [5-13], our series is the most representative in number of cases of any gestational age and preterm age using the JM105 device [14].

The use of TCB as a screening method for neonatal hyperbilirubinemia is included in clinical practice guidelines. The American Academy of Pediatrics recommends it as a screening system in neonates $>35$ weeks of gestational age [4, 15]. In 2000, Bhutani et al. conducted a study enrolling almost 500 infants which showed the efficacy of TCB in methods. The $y$-axis shows the absolute difference between the two methods (TSB-PTCB; TSB-UTCB)

predicting the risk of severe hyperbilirubinemia and the indication of phototherapy [2]. In our work we have obtained adequate results about the usefulness of TCB as a screening tool, similar to those already described [5, 7-9, 16, 17]. The good correlation is maintained in the preterm group, as Nagar's review (22 studies) had stated, while suggesting a better accuracy with the bilirubinometer JM-103 compared with other devices [18].

Tan and Dong observed that the beginning of phototherapy reduced the correlation of TCB with TSB in skin exposed to light [19]. This fact has been confirmed by other authors [7, 16, 20, 21]. A systematic review and metaanalysis conducted in 2016 exposes the dubious utility of TCB in skin exposed to phototherapy [4]. Our study has 


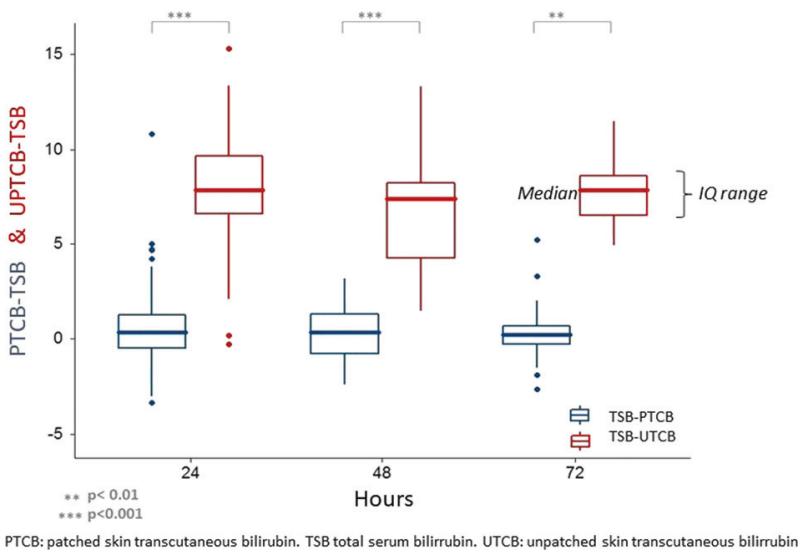

Fig. 4 Graph depicting the difference between TCB on patched skin (PTCB) or unpatched skin (UTCB) and TSB at various time moments (hours of phototherapy). Mean of differences and interquartile range

also shown a significant decrease in the correlation between TCB and TSB in light exposed skin, with mean differences exceeding 6-8 points. This happens even in preterm patients, contrary to that affirmed by other authors $[5,17]$.

On the usefulness of covering the skin from exposure to phototherapy, in 1983, Hegyi et al. showed that only the TCB measured in uncovered skin changes during phototherapy, while measurements on covered skin continue to predict the TSB with sufficient reliability [20]. Other subsequent studies carried out with the Bilicheck $^{\circledR}$ bilirubinometer corroborated this statement [5-8, 22]. Zecca et al. [7] used a photo-opaque patch of $2.5 \mathrm{~cm}$ in diameter designed for treatment during phototherapy (BiliEclipse, Respironics ${ }^{\circledR}$ ) located on newborn's forehead. They observed that TCB had a slight tendency to overestimate TSB when bilirubin levels were high and that TCB started to underestimate TSB after $96 \mathrm{~h}$ of treatment, but in general the correlation shown was good and similar to our findings. Other authors obtained similar results using the same device [5, 6, 8]. However, in a study published in 2017 by Murli performed in 100 newborns, they found a bad correlation between the TSB and TCB before, during and after the treatment [10]. They also used the Bilicheck ${ }^{\circledR}$ but performed TCB measurements in a different area of the skin (sternum) covered by the BiliEclipse ${ }^{\circledast}$ patch.

Regarding our bilirrubinometer, JM-105, or its previous model JM-103, there are scarce studies that have evaluated the usefulness of TCB in covered skin in term children. The prospective study conducted by Casnocha with the JM-103 made determinations only after the end of phototherapy. The reliability of the TCB was low, despite being measured on the unexposed skin (abdomen covered with the diaper), although higher than in exposed areas [3]. Perhaps the good results obtained in our study are related to the place used for the measurements on covered skin (sternum) recommended by the manufacturer.
With respect to the use of TCB on covered skin during phototherapy in preterm infants the studies show contradictory results. In the study by Zecca [7] they found a better correlation in premature than in term infants, like we have done. Similar results are those found by Pendse et al. [13] who employed a methodology similar to ours (aluminum photoprotection system and JM-105). These authors highlighted better results in children under 32 weeks. On the contrary, in the work carried out by Radfar with Bilicheck ${ }^{\circledR}$ they found a worse correlation in the preterm group [5].

In terms of extremely low birth weight premature babies (EBLW), De Luca and Dell'Orto [11] obtained readings in the forehead on skin covered by the cap of the CPAP, and found a good correlation after 4-6 h from the start of phototherapy, with a tendency towards overestimation at high levels of bilirubin. In another study carried out by Bhargava [12], they employed the BiliEclipse ${ }^{\circledR}$ patch coverage, but measurements were made on the back. They observed a tendency to overestimation in the TCB determinations performed on covered skin and to underestimation in the determinations made on skin exposed to light.

Regarding the most premature patients there is controversy about the suitability of placing a patch (given the skin fragility) or not. There are authors such as Cucuy or Roshsiwatmo, who found a good correlation between TSB and TCB on exposed skin measured with the JM-103 bilirubinometer in the sternum, after the initiation of phototherapy in preterm infants $[17,23]$. Perhaps the immaturity of the cutaneous barrier of the very premature and its dermal kinetics influences these results, favouring that the reading in uncovered skin is more similar to the TSB. Our EBLW sample is too small to draw conclusions. All results are limited to Caucasian race neonates.

In our series the good correlation between TSB and PTCB improves as the treatment time progresses, reaching the maximum correlation $(0.27 \mathrm{mg} / \mathrm{dL})$ at $48 \mathrm{~h}$, showing the usefulness of this technology for the follow-up during phototherapy. The best agreement as the hours of treatment and postnatal age increase could be related to the balance established between the TSB and the TCB in the skin with time. This effect has been observed in term and preterm children.

Finally, in relation to clinical application of our findings, we note that the differences in serum and transcutaneous values in covered skin barely exceed two points of difference in the most unfavorable and infrequent scenario. Therefore it can be recommended as a follow-up method during treatment, with the advantage of fewer blood tests. However, it would be advisable to confirm the value of TCB with a blood test in those cases in which a difference of two points in the bilirubin value implies a change in the therapeutic attitude. 
Acknowledgements We would like to thank all the nurse staff of the Neonatology Unit of Alvaro Cunqueiro Hospital for their help in their recollection of bilirrubin measurements.

\section{Compliance with ethical standards}

Conflict of interest The authors declare that they have no conflict of interest.

Informed consent Informed consent was obtained from parents or legal guardians of all the patients for the participation of their children in the study which was approved by the Local Ethics Committee.

Publisher's note Springer Nature remains neutral with regard to jurisdictional claims in published maps and institutional affiliations.

Open Access This article is licensed under a Creative Commons Attribution 4.0 International License, which permits use, sharing, adaptation, distribution and reproduction in any medium or format, as long as you give appropriate credit to the original author(s) and the source, provide a link to the Creative Commons license, and indicate if changes were made. The images or other third party material in this article are included in the article's Creative Commons license, unless indicated otherwise in a credit line to the material. If material is not included in the article's Creative Commons license and your intended use is not permitted by statutory regulation or exceeds the permitted use, you will need to obtain permission directly from the copyright holder. To view a copy of this license, visit http://creativecommons. org/licenses/by/4.0/.

\section{References}

1. Samiee-Zafarghandy S, Feberova J, Williams K, et al. Influence of skin colour on diagnostic accuracy of the jaundice meter JM 103 in newborns. Arch Dis Child Fetal Neonatal Ed. 2014;99:80-4.

2. Bhutani VK, Gourley GR, Adler S, Kreamer B, Dalin C, Johnson LH. Noninvasive measurement of total serum bilirubin in a multiracial predischarge newborn population to assess the risk of severe hyperbilirubinemia. Pediatrics 2000;106:E17.

3. Casnocha Lucanova L, Matasova K, Zibolen M, Krcho P. Accuracy of transcutaneous bilirubin measurement in newborns after phototherapy. J Perinatol 2016;36:858-61.

4. Nagar G, Vandermeer B, Campbell S, Kumar M. Effect of phototherapy on the reliability of transcutaneous bilirubin devices in term and near-term infants: a systematic review and meta-analysis. Neonatology 2016;109:203-12.

5. Radfar M, Hashemieh M, Shirvani F, Madani R. Transcutaneous bilirubinometry in preterm and term newborn infants before and during photo-therapy. Arch Iran Med. 2016;19:323-8.

6. Alsaedi SA. Transcutaneous bilirubin measurements can be used to measure bilirubin levels during phototherapy. Int $\mathrm{J}$ Pediatr 2018;2018:4856390.
7. Zecca E, Barone G, De Luca D, Marra R, Tiberi E, Romagnoli C. Skin bilirubin measurement during phototherapy in preterm and term newborn infants. Early Hum Dev. 2009;85:537-40.

8. Fonseca R, Kyralessa R, Malloy M, Richardson J, Jain SK. Covered skin transcutaneous bilirubin estimation is comparable with serum bilirubin during and after phototherapy. J Perinatol 2012;32:129-31.

9. Jnah A, Newberry DM, Eisenbeisz E. Comparison of transcutaneous and serum bilirubin measurements in neonates 30 to 34 weeks' gestation before, during, and after phototherapy. Adv Neonatal Care. 2018;18:144-53.

10. Murli L, Thukral A, Sankar MJ, Vishnubhatla S, Deorari AK, Paul VK. Reliability of transcutaneous bilirubinometry from shielded skin in neonates receiving phototherapy: a prospective cohort study. J Perinatol. 2017;37:182-7.

11. De Luca D, Dell'Orto V. Patched skin bilirubin assay to monitor neonates born extremely preterm undergoing phototherapy. J Pediatr 2017;188:122-7.

12. Bhargava V, Tawfik D, Niebuhr B, Sunil K. Jain. Transcutaneous bilirubin estimation in extremely low birth weight infants receiving phototherapy: a prospective observational study. BMC Pediatrics. 2018;18:227.

13. Ebbesen F, Rasmussen LM, Wimberley PD. A new transcutaneous bilirubinometer, BiliCheck, used in the neonatal intensive care unit and the maternity ward. Acta Paediatr. 2002;91:203-11.

14. Pendse A, Jasani B, Nanavati R, Kabra N. Comparison of transcutaneous bilirubin measurement with total serum bilirubin levels in preterm neonates receiving phototherapy. Indian Pediatr 2017;54:641-3.

15. American Academy of Pediatrics Subcommittee on Hyperbilirubinemia. Management of hyperbilirubinemia in the newborn infant 35 or more weeks of gestation. Pediatrics 2004;114:297-316.

16. Jangaard K, Curtis H, Goldbloom R. Estimation of bilirubin using BiliChektrade mark, a transcutaneous bilirubin measurement device: effects of gestational age and use of phototherapy. Paediatr Child Health. 2006;11:79-83.

17. Cucuy M, Juster-Reicher A, Flidel O, Shinwell E. Correlation between transcutaneous and serum bilirubin in preterm infants before, during and after phototherapy. J Matern Fetal Neonatal Med. 2018;31:1323-6.

18. Nagar G, Vandermeer B, Campbell S, Kumar M. Reliability of transcutaneous bilirubin devices in preterm infants: a systematic review. Pediatrics 2013;132:871-81.

19. Tan KL, Dong F. Transcutaneous bilirubinometry during and after phototherapy. Acta Paediatr. 2003;92:327-31.

20. Hegyi T, Hiatt IM, Gertner IM, Zanni R, Tolentino T. Transcutaneous bilirubinometry II. Dermal bilirubin kinetics during phototherapy. Pediatr Res 1983;17:888-91.

21. Katayama Y, Enomoto M, Kikuchi S. Transcutaneous bilirubin measurement during phototherapy in term neonates. Pediatrics Int. 2017;59:686-90.

22. Nanjundaswamy S, Petrova A, Mehta R, Hegyi T. Transcutaneous bilirubinometry in preterm infants receiving phototherapy. Am J Perinatol. 2005;22:127-31.

23. Rohsiswatmo, et al. Agreement test of transcutaneous bilirubin and bilistick with serum bilirubin in preterm infants receiving phototherapy. BMC Pediatrics. 2018;18:315. 